\title{
EROSÃO EM FALÉSIAS COSTEIRAS E MOVIMENTOS DE MASSA NO RIO GRANDE DO NORTE, NORDESTE DO BRASIL
}

\author{
COASTAL CLIFF EROSION AND MASS MOVEMENTS IN RIO GRANDE DO NORTE, \\ NORTHEASTERN BRAZIL
}

\section{Breno Marques Ferreira da SILVA, Olavo Francisco dos SANTOS JÚNIOR, Osvaldo de FREITAS NETO, Ada Cristina SCUDELARI}

Universidade Federal do Rio Grande do Norte. Avenida Senador Salgado Filho, 3000 - Lagoa Nova, Natal - RN.

E-mails: brenomarquesfs@gmail.com; olavo@ct.ufrn.br; osvaldocivil@ufrn.edu.br; ada@ct.ufrn.br

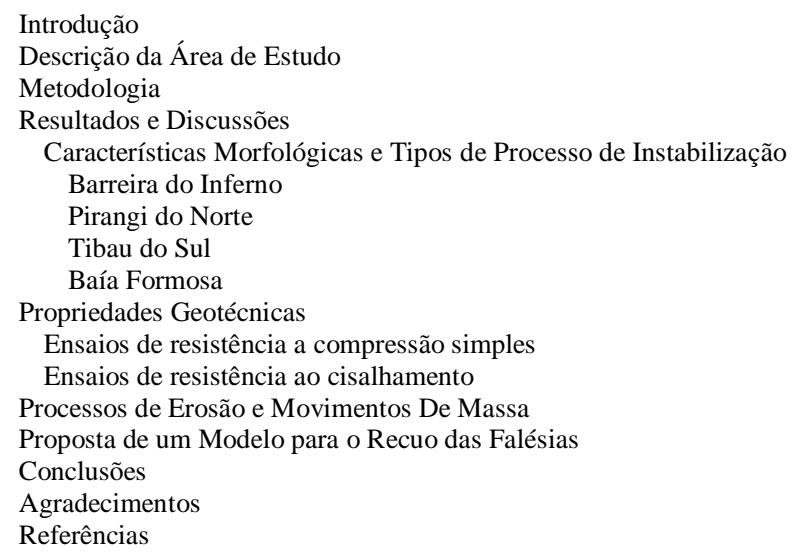

RESUMO - A região costeira do Estado do Rio Grande do Norte (RN), no nordeste do Brasil é constituída por materiais sedimentares que formam tabuleiros costeiros, dunas, falésias e praias arenosas. A exuberância paisagística dessa área representa um atrativo para a ocupação humana e desenvolvimento de atividades turísticas. Esse processo de urbanização potencializa a ocorrência de movimentos de massa nas falésias, resultante do aumento da carga no topo das falésias, remoção da vegetação e aumento da erosão superficial. Estudos anteriores desenvolvidos nas falésias da região indicam que a linha de costa se encontra em processo de recuo, o que põe em risco a infraestrutura instalada e seus usuários. O presente artigo visa compreender os mecanismos de movimentos de massas que ocorrem nas falésias e resultam no seu recuo. O trabalho sistematiza as informações existentes, adiciona observações de campo e propõe um modelo conceitual contemplando os mecanismos de ruptura e processos erosivos identificados, ao longo da porção sul do litoral Oriental do Estado do Rio Grande do Norte. Os principais mecanismos identificados estão diretamente relacionados à erosão superficial em episódios de chuvas intensas, umedecimento do material e a erosão basal, caracterizada pela remoção de material do pé das falésias, devido a ação das ondas.

Palavras-chave: Mecanismos de ruptura, Recuo de falésias, Movimentos de massa, Erosão, Formação Barreiras.

ABSTRACT - The coast of the State of Rio Grande do Norte (RN) at the Northeast of Brazil is formed by sedimentary materials that form tablelands, dunes, cliffs and sandy beaches. The natural beauties of this area motivate occupation and tourist activities. This process of urbanization enhances mass movements, resulting from the increase of load, superficial erosion and removal of vegetation. Previous studies show that the coastline is in the process of retreat. This fact represents hazard to population and tourism industry. The present paper aims to better understand the mechanisms of mass movements and consequently seacliff retreat. Also, this research summarizes existing information, adds field observations and proposes a conceptual model that explains the mechanisms os failure and erosive processes identified. Additionally erosive processes are identified along the studied area. The main mechanisms identified are directly related to surface erosion, wetting of the material and basal erosion.

Keywords: Failure Mechanisms, Cliff Retreat, Mass Movements, Erosion, Barreiras Formation.

\section{INTRODUÇÃO}

A região costeira consiste na transição entre o continente e o mar, tendo como interface a linha de costa. Essa região está submetida a diversos processos naturais que resultam em variações sazonais na posição da linha de costa. Tais variações resultam da retirada e da alimentação de sedimentos na praia pela ação de correntes, ondas e ventos. Quando o volume de material retirado é igual ao que é acrescido pelos processos vigentes, se estabelece um equilíbrio dinâmico. Esse equilíbrio pode ser quebrado por alterações antrópicas ou mesmo naturais, o que leva a processos de erosão, quando o volume retirado é maior que o acrescido ou em acreção quando ocorre o contrário. $\mathrm{O}$ estudo dessa dinâmica é importante no sentido de identificar áreas adequadas e impróprias para a ocupação, tendo em vista o grande atrativo econômico e 
ambiental para uso e ocupação do solo nessa região.

Os processos erosivos costeiros resultam no movimento da linha de costa em direção ao continente. Esse é um processo dinâmico natural que envolve perdas de terras e mudanças nas paisagens naturais, que é governado, principalmente pelas condições geológicas, marinhas, climáticas e antrópicas da região (Sunamura, 2015; Brooks et al., 2012; Belov et al., 1999). A ocupação desordenada da linha de costa causa um importante conflito socioeconômico, o qual envolve riscos potenciais à população. Esse conflito se torna evidente devido ao desenvolvimento de infraestrutura nas cidades litorâneas, à elevada densidade populacional dessas áreas e às alterações climáticas que tendem a acelerar os processos erosivos atuantes no litoral.

O litoral do estado do Rio Grande do Norte é formado por praias arenosas, falésias e campos de dunas. As praias arenosas resultam da deposição marinha de sedimentos em função da dinâmica costeira. Esses sedimentos são transportados pela ação eólica e depositados quando há mudança de direção ou diminuição da velocidade do vento, formando campos de dunas. Em boa parte do litoral do RN ocorrem as falésias, as quais consistem em desníveis no relevo, formados principalmente pela ação do mar em rochas sedimentares da Formação Barreiras. Outra feição típica da costa do RN é a presença de arenitos de praia paralelos a linha de costa, os quais servem de proteção contra ação das ondas.

O estudo da estabilidade de falésias é importante, uma vez que em muitos casos, as consequências de rupturas envolvem perdas de residências e infraestrutura (Collins \& Sitar, 2008). Esse tema é motivo de diversas pesquisas por todo o mundo, tais como: na América do Sul (Blanco-Chao et al., 2014), Estados Unidos da América (Young \& Ashford, 2008; Young, 2015), Inglaterra (Quinn et al., 2009; Moore \& Davis, 2014), Itália (Martino \& Mazzanti, 2013). Isso decorre da necessidade de se entender as causas das rupturas, a sua relação com as características dos materiais, bem como os mecanismos e fenômenos que contribuem diretamente para o recuo costeiro.

As falésias presentes na costa do RN têm sido objeto de estudos com vistas a identificação dos tipos de movimentos de massas e na compreensão dos mecanismos de recuo (Braga, 2005; Scudelari et al., 2005; Santos Jr. et al., 2006; Nascimento, 2009; Santos Jr. et al., 2011), à avaliação das propriedades geotécnicas dos materiais que formam os taludes (Silva, 2003; Severo, 2005; Severo, 2011; Barbosa, 2017; Taquez, 2017) e à análise de sua estabilidade (Severo, 2005; Souza Jr., 2013; Ribeiro, 2015; Silva et al., 2016; Taquez et al., 2016 Barbosa, 2017; Taquez, 2017). Tais estudos se referem a áreas específicas. $\mathrm{O}$ presente trabalho revisa, reinterpreta e sistematiza o conhecimento produzido nos estudos relacionados às falésias do litoral do $\mathrm{RN}$ e propõe um modelo que representa o padrão de recuo vigente na região.

\section{DESCRIÇÃO DA ÁREA DE ESTUDO}

O litoral oriental do $\mathrm{RN}$, nordeste do Brasil, apresenta direção aproximada Norte-Sul, limitando-se ao sul pelo Rio Sagi (município de Baía Formosa) e ao norte pelo Cabo Calcanhar, no município de Touros (Muehe, 2006; Amaro et al., 2012). Este setor possui $166 \mathrm{~km}$ de extensão total, distribuídos em $101 \mathrm{~km}(61 \%)$ de praias arenosas planas e estreitas e $65 \mathrm{~km} \mathrm{(39 \% )} \mathrm{de} \mathrm{falésias} \mathrm{ativas}$ da Formação Barreiras (Muehe, 2006). A área objeto de estudo está situada no litoral oriental do $\mathrm{RN}$, situa-se entre o limite sul (Baía Formosa) e ao norte pelo município de Natal. Toda a área de estudo possui $80 \mathrm{~km}$ de extensão total. A figura 1 mostra a localização da área estudada e o contexto geológico-geomorfológico regional.

De forma geral, os elementos de relevo predominantes no litoral são os tabuleiros costeiros, os campos de dunas e as planícies. Além disso, observa-se também a presença de linhas de recifes de arenitos, aproximadamente paralelas a linha de costa, que alteram o padrão de arrebentação das ondas (Muehe, 2006).

Os Tabuleiros Costeiros consistem em um relevo plano com altitude variando de 40 a 120 metros. Nas regiões próximas a linha de costa, em alguns trechos esses tabuleiros entram em contato com o mar, provocando a formação de falésias. Assim, as falésias objeto do presente estudo, consistem na borda dos tabuleiros, as quais foram formadas principalmente pela ação erosiva do mar. As falésias são consideradas ativas quando ainda se verifica a ação das ondas e correntes na sua base. Quando o mar não atinge o pé da encosta, a falésia é considerada inativa ou morta. $\mathrm{Na}$ área 
estudada observam-se falésias com altura de até 50 metros e ângulo de inclinação variando de $40^{\circ}$ a $90^{\circ}$ (Figura 2a).

Os campos de dunas se localizam em regiões próximas ao litoral e resultam do acúmulo de sedimentos arenosos transportado pelo vento, a partir das praias arenosas que formam a planície marinha (Figura $2 b$ ). Na região observa-se também a ocorrência de planícies fluviais nos rios que cortam a região.

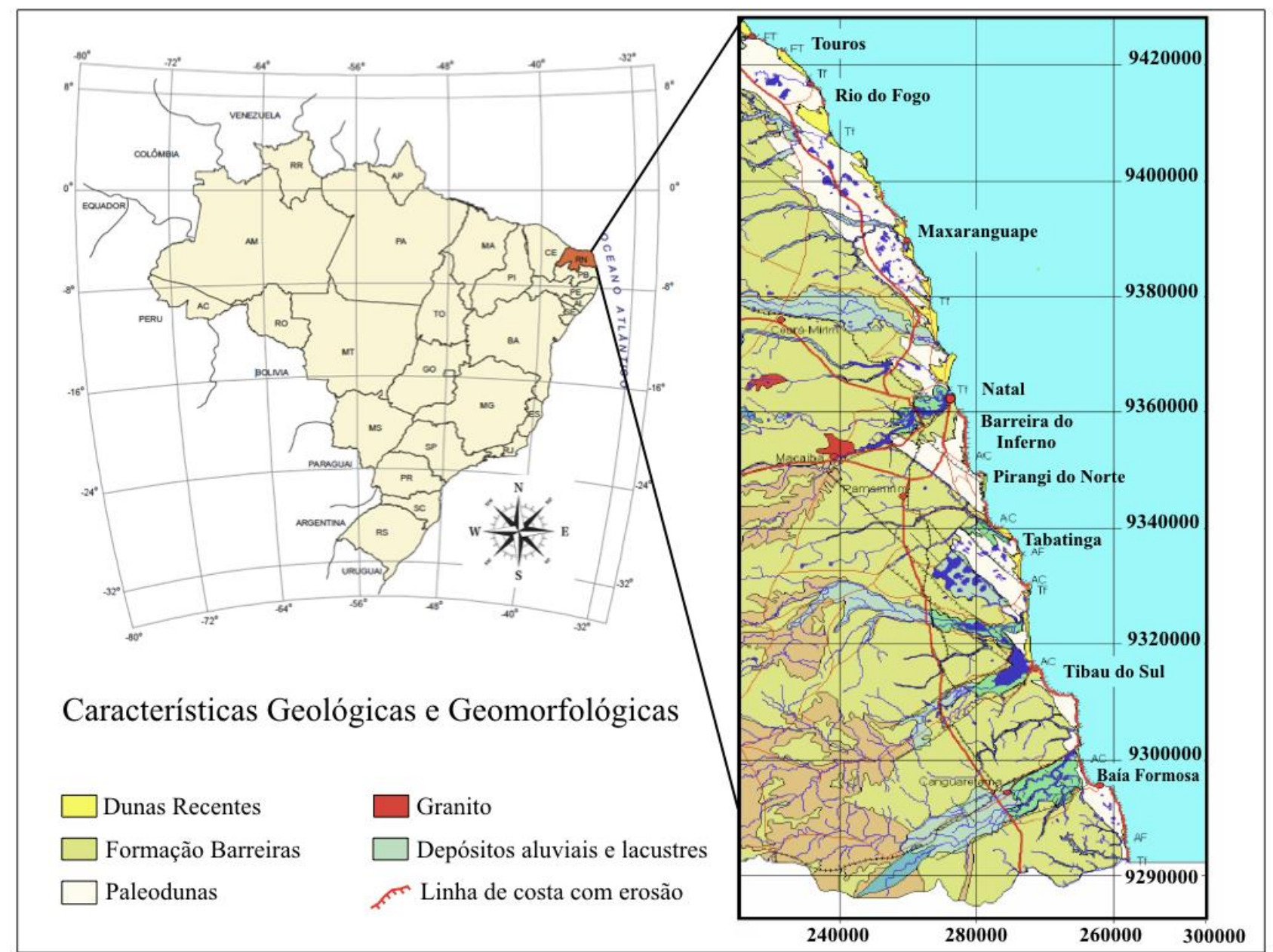

Figura 1 - Mapa do litoral do RN com destaque para as áreas estudadas, da porção mais ao sul em direção ao norte: Baía formosa, Tibau do Sul, Pirangi do Norte, Barreira do Inferno. (Adaptado de Diniz, 2002).

Em termos geológicos, os tabuleiros consistem de material sedimentar da Formação Barreiras, depositados a partir do Mioceno até o Plioceno. A Formação Barreiras é composta principalmente por arenitos finos a médios, ou conglomeráticos, avermelhados, com intercalações sílticas, argilosa e cauliníticas; por vezes síltico-argilosos e argilitos depositados em ambiente aluvial (Diniz, 2002; Piérri, 2008). Em alguns locais ocorre a cimentação ferruginosa dos sedimentos, o que formam camadas com maior rigidez e resistência que as camadas adjacentes. A diversidade das características da área, sobretudo na geologia e das propriedades de resistência dos sedimentos, exerce influência direta no entendimento dos processos erosivos e movimentos de massa.

$\mathrm{Na}$ área de estudo, destaca-se o domínio das ondas de sudeste, as quais são responsáveis por uma deriva litorânea no sentido Sul-Norte, atuando praticamente durante todo o ano. Ao longo da linha da costa do RN, registra-se uma grande sequência de baías em forma de zeta. Essa peculiaridade, lhe confere uma assinatura característica diferenciada, com relação ao restante da costa brasileira (Diniz, 2002). A altura máxima das marés varia de $2,5 \mathrm{~m}$ a $3,3 \mathrm{~m}$, respectivamente durante marés de quadratura e sizígia (Vital et al., 2008).

A área apresenta de forma geral clima tropical chuvoso quente, com temperatura média anual de $25,7^{\circ} \mathrm{C}$ e umidade relativa média anual variando de $74 \%$ a $80 \%$. A estação chuvosa está compreendida entre os meses de fevereiro a agosto, quando os totais mensais (média) variam de 90 a $230 \mathrm{~mm}$ e precipitações anuais de aproximadamente $1261 \mathrm{~mm}$ (Severo, 2005; Severo 2011; Souza Júnior, 2013; Diniz, 2002; Nascimento, 2009; Barbosa, 2017).

Diferentes regiões foram estudadas ao longo do 
litoral oriental do RN, destacando-se as áreas com ocupação humana, Tibau do Sul (Scudelari et al., 2005; Santos Jr. et al., 2006; Severo, 2005; Ribeiro, 2015; Silva et al., 2016; Taquez et al., 2016), Baía
Formosa (Souza Júnior, 2013), Pirangi do Norte (Nascimento, 2009), bem como a Barreira do Inferno (Barbosa, 2017; Taquez, 2017) a qual apresenta-se livre de interferências antrópicas.

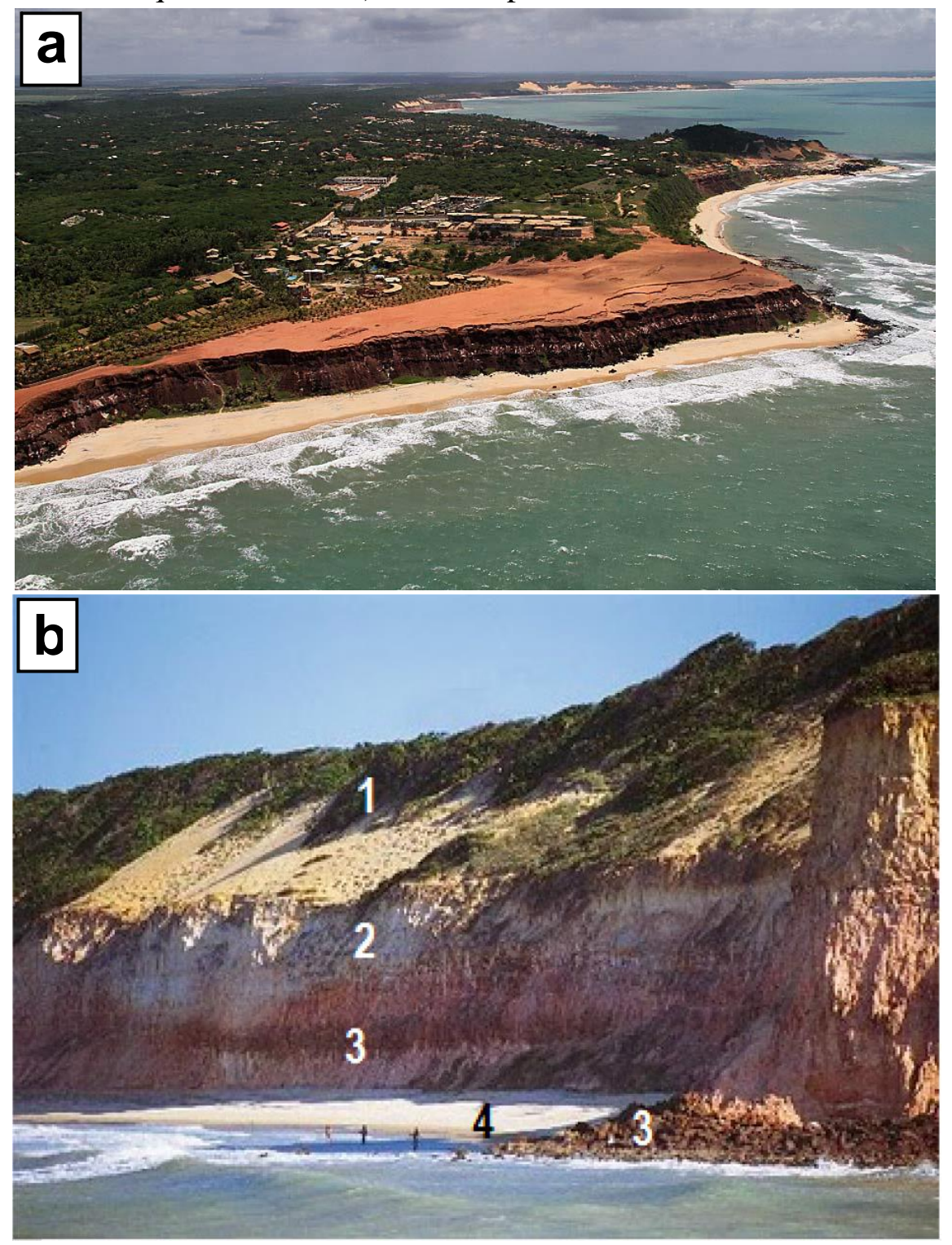

Figura 2 - a) Foto aérea do Chapadão situado na Praia de Pipa/RN, litoral sul do Rio Grande do Norte. Observar a presença de Tabuleiro Costeiro e Falésias com inclinação em torno de $40^{\circ}$, as quais consistem na borda dos tabuleiros (Fonte: caninde.soares.com). b) Dunas (1) cobrindo falésia da formação Barreiras (2) e (3); Praia arenosa (4).

\section{METODOLOGIA}

Inicialmente foi feito um levantamento sobre os estudos já realizados na região costeira oriental do RN, a sul de Natal envolvendo processos erosivos e movimentos de massas em falésias.

Foram identificados trabalhos sobre tipos de movimentos de massas, propriedades mecânicas dos materiais que formam as falésias e mecanismos de recuo das falésias. Os estudos anteriores enfocam aspectos de áreas específicas. No sentido Norte para Sul foram analisados trabalhos das seguintes áreas: Barreira do Inferno, Pirangi do Norte, Tibau do Sul e Baía

\section{Formosa.}

Os trabalhos foram analisados com o objetivo de realizar a interpretação conjunta dos dados, tendo em vista que embora desenvolvidos em áreas distintas, se referem as mesmas unidades geomorfológicas e geológicas. Em seguida, todas as áreas foram objeto de inspeções de campo detalhadas com o objetivo de confirmar os aspectos mencionados nos trabalhos anteriores. Nesse sentido, foram observadas as características geométricas das falésias (altura e inclinação), a existência ou não de proteção na base da falésia, seja pela presença de faixa de 
praia ou de blocos de arenito, as características mecânicas dos materiais por meio expedito (tátilvisual) e identificados os tipos de movimentos de massas da área.

A partir da análise dos dados de propriedades físicas e mecânicas foram feitas análises estatísticas de índice de vazios, resistência a compressão simples e dos parâmetros de resistência dos materiais (coesão e ângulo de atrito). Foram também observadas e analisadas as alterações nos parâmetros de resistência em função do aumento do teor de umidade do material com vistas a avaliar o efeito da infiltração de água sobre as condições de estabilidade das falésias.

Por fim, com base na interpretação conjunta das observações de campo, da comparação com os mecanismos descritos nos diversos trabalhos e das análises das propriedades geotécnicas dos materiais das falésias foram propostos modelos conceituais que explicam o processo de recuo da linha de costa da área estudada.

\section{RESULTADOS E DISCUSSÕES}

\section{Características Morfológicas e Tipos de Processo de Instabilização Barreira do Inferno}

A Barreira do Inferno está localizada na Rota do Sol, a aproximadamente $12 \mathrm{~km}$ ao Sul de Natal/RN, no município de Parnamirim/RN. Trata-se de uma área militar conhecida como Centro de Lançamentos da Barreira do Inferno (CLBI), indexado ao Departamento de Ciência e Tecnologia Aeroespacial - DCTA do Governo Brasileiro. O trecho estudado é uma área protegida, a qual compreende aproximadamente 2,5 km de extensão (Taquez, 2017).

As falésias apresentam alturas de 25 a $60 \mathrm{~m}$ e inclinações variando de $45^{\circ}$ a $80^{\circ}$ (Taquez, 2017). Os principais movimentos de massa (tombamentos, quedas de blocos e escorregamentos) ocorrem em locais de maior presença de fendas de tração (Taquez, 2017). Não há registros de movimentos de massa de grande profundidade na área (Barbosa, 2017).

Por se tratar de área militar protegida, o trecho estudado encontra-se livre de interferências antrópicas, tais como residências e infraestruturas urbanas. A cobertura vegetal da área é formada por mata atlântica, vegetação de tabuleiro e restinga (Barbosa, 2017).

\section{Pirangi do Norte}

A praia de Pirangi do Norte/RN está localizada no município de Parnamirim/RN, à aproximadamente $20 \mathrm{~km}$ ao sul de Natal. O trecho estudado abrange uma faixa de praia de cerca de $1 \mathrm{~km}$ de extensão (da praia de Cotovelo até a praia de Pirangi do Norte/RN).

Toda essa área é caracterizada pela presença de tabuleiros na parte superior, falésias e a planície costeira na parte inferior, as quais observa-se a ocorrência de recifes de arenitos atuando como proteção natural das encostas (Nascimento, 2009).
A área de Pirangi do Norte/RN é consideravelmente ocupada pelo homem, com diversos empreendimentos imobiliários na linha de encosta (Figura 3.a). Observa-se a contribuição antrópica em processos erosivos, através do despejo de águas pluviais na zona de praia (Nascimento, 2009). Algumas áreas são recobertas por vegetação de restinga, cerrado, caatinga e cobertura vegetal da mata-atlântica (Piérri, 2008). A maior parte da área é coberta por vegetação tanto na sua borda, como na face das encostas (Nascimento, 2009).

Em vários trechos observam-se indícios de erosão, ocasionados pelo solapamento do sopé da falésia, resultado da ação direta do mar (Figura 3.b). Além disso, em alguns pontos percebe-se a ocorrência de movimentos de massa tais como, deslizamentos e tombamentos (Nascimento, 2009).

\section{Tibau do Sul}

O município de Tibau do Sul/RN localiza-se a aproximadamente $60 \mathrm{~km}$ ao sul de Natal/RN. A área estudada de Tibau do Sul/RN é limitada pela margem sul da laguna Guaraíras ao norte; e pelo canal do Rio Catú, o que corresponde a um segmento de $16 \mathrm{~km}$.

Essa região é formada predominantemente pela Formação Barreiras, onde ao longo de toda a sua extensão ocorrem falésias ativas com altura variando de 20 a 40 metros. Os perfis mais comuns na região apresentam inclinações próximas de $90^{\circ}$, até inclinações de aproximadamente $45^{\circ}$ (Silva et al., 2016).

Observam-se processos erosivos e de movimentos de massa associados principalmente a fortes chuvas e ação das ondas direta na base das falésias. Os movimentos de massa mais observados em toda a área são as quedas de blocos, que acumulam sedimentos (talus) na base das falésias (Santos Jr. et al., 2006). 
Nos períodos chuvosos ocorre maior falésias, que somam àqueles causados incidência de processos de desestabilização nas juntamente pela ação das águas do mar

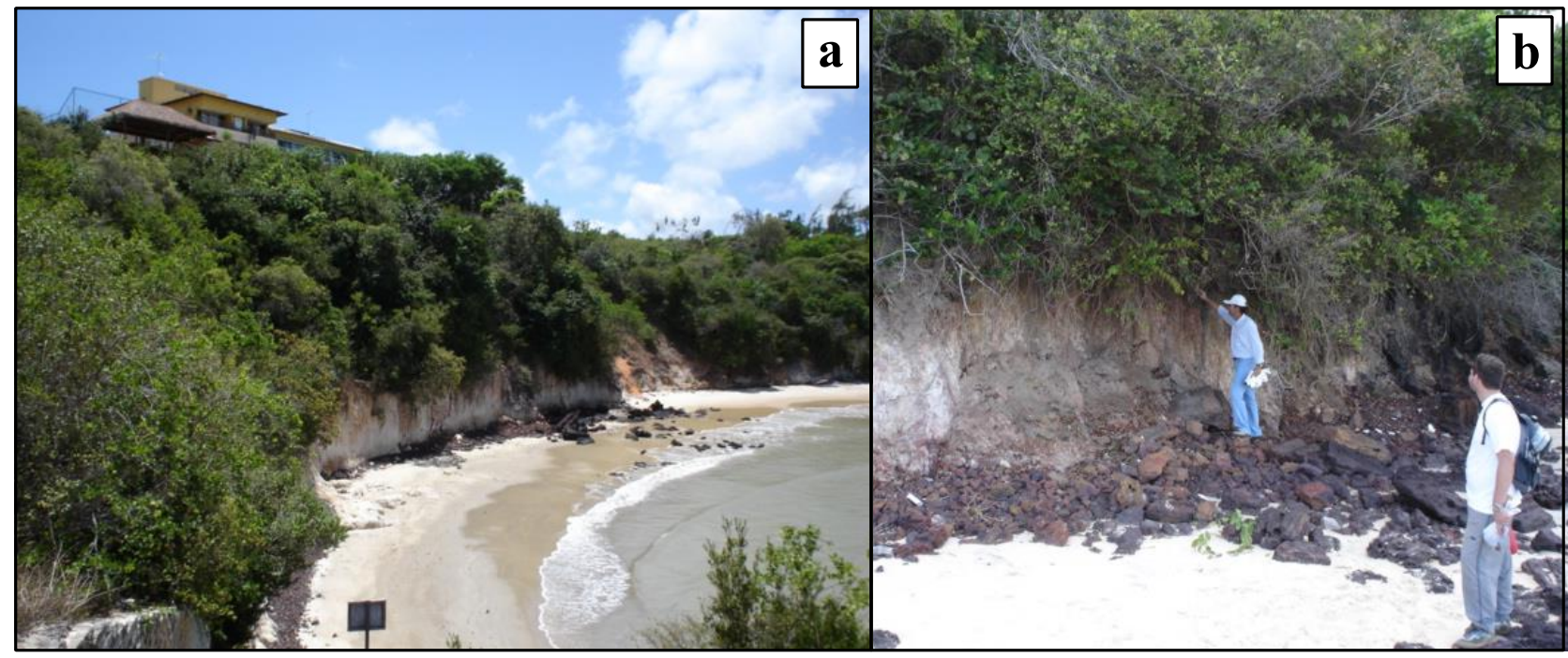

Figura 3 - Fotos da praia de Pirangi do Norte. a) Ocupação humana na borda das falésias mediante empreendimentos turísticos; b) Presença de vegetação e indícios de erosão (solapamento) na base das falésias (Retirado de Nascimento, 2009).

Em alguns setores, a base das falésias encontra-se protegida da ação direta das ondas por meio de blocos de arenitos com cimentação ferruginosa que caíram da parte superior.

Em outros setores observa-se a escavação na base da falésia, que provoca o solapamento da parte superior, com consequente queda do material.

A figura 4 mostra características típicas das falésias da região, com destaques para a formação de incisões basais, a evidência de queda de blocos e acúmulo de material na base.

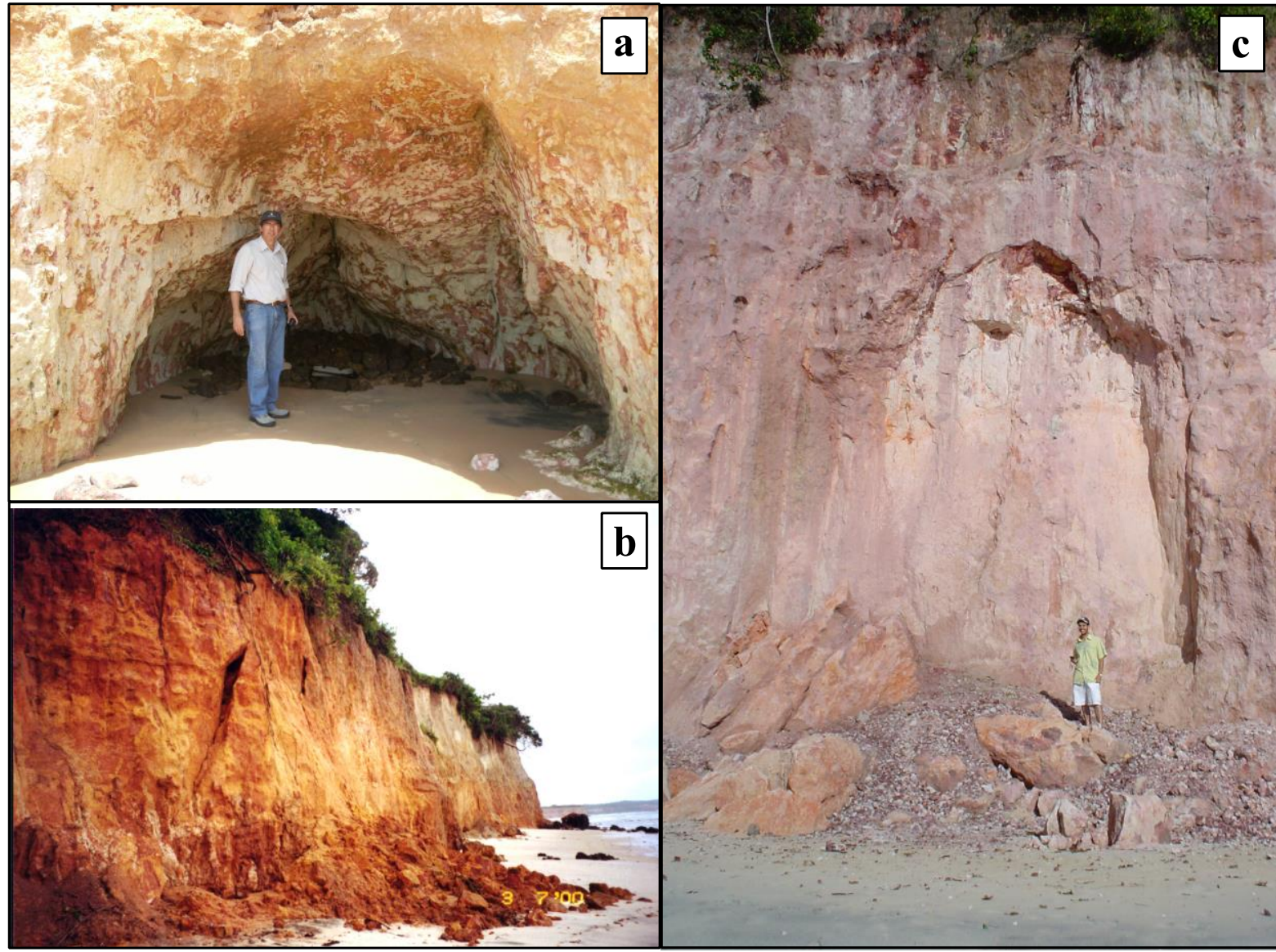

Figura 4 - Fotos da Região de Tibau do Sul. a) Formação de enorme incisão na base da falésia, com acúmulo de material abaixo da incisão; b) Visão geral das falésias, evidenciando movimentos de massa recentes e acúmulo de talus na base; c) Desplacamento de bloco. 


\section{Baía Formosa}

O município de Baía Formosa/RN, situa-se a cerca de $100 \mathrm{~km}$ ao sul da capital Natal/RN. O trecho estudado estende-se por uma faixa de aproximadamente $1200 \mathrm{~m}$ ao longo da praia do Porto.

Em geral, as falésias da Praia do Porto apresentam diferentes inclinações entre $40^{\circ}$ e $90^{\circ}$ e altura variando de 3,5 a $15 \mathrm{~m}$. Essa região é caracterizada pela presença de tabuleiros costeiros na parte superior, falésias encobertas por depósitos dunares e a planície costeira na parte inferior (Souza Júnior, 2013). É possível perceber as diferentes camadas na face das falésias da Formação Barreiras, as quais apresentam diferentes níveis de cimentação (Figura 5).

Os principais movimentos de massa identificados em quase toda a extensão analisada são quedas de detritos, quedas de blocos, tombamentos e pequenos deslizamentos. Além disso, em alguns trechos, observa-se incisões basais, causadas pela ação das ondas no pé da falésia (Souza Júnior, 2013)

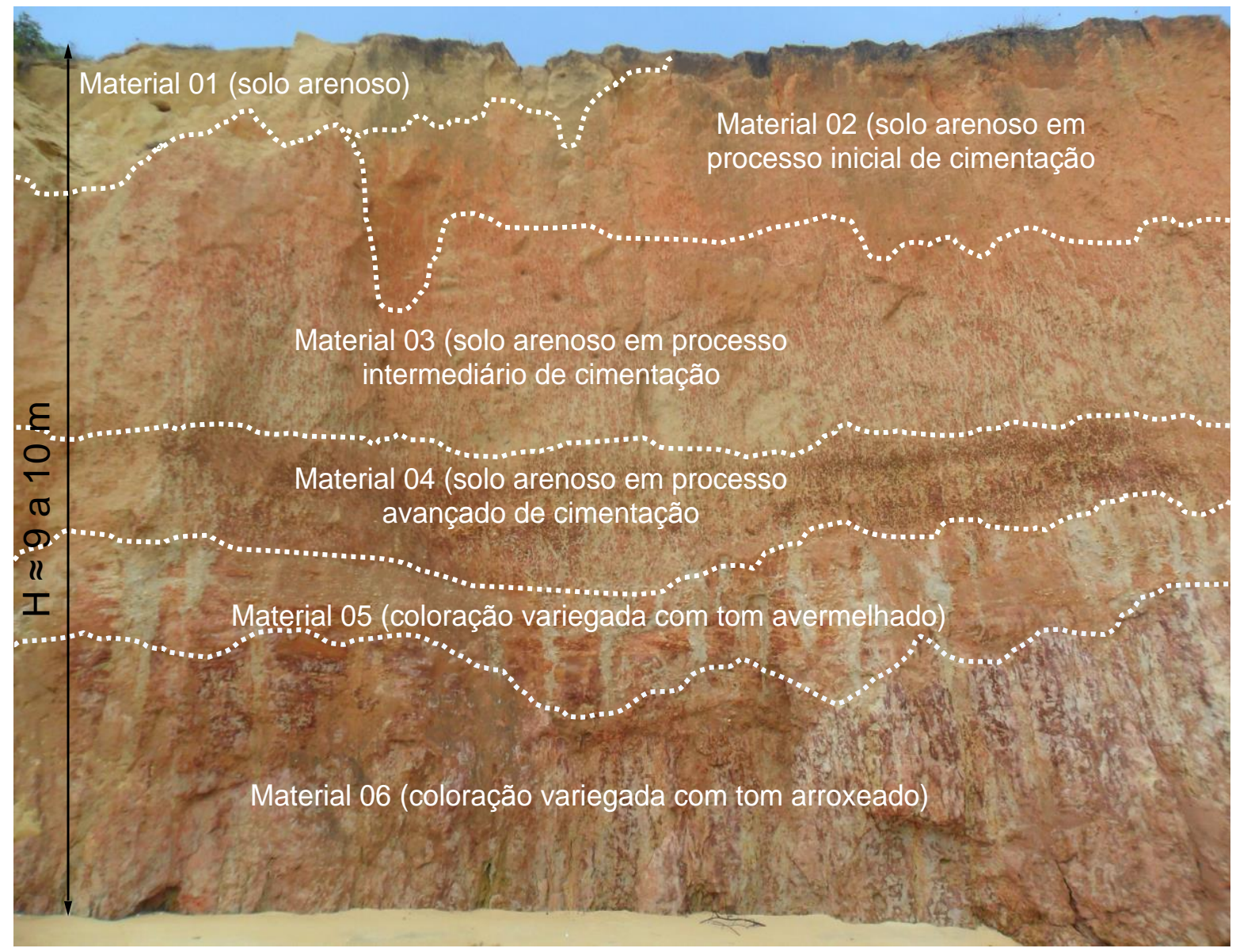

Figura 5 - Formação de diferentes camadas constituídas de materiais em estágios de cimentação diferenciados (Souza Júnior, 2013).

\section{PROPRIEDADES GEOTÉCNICAS}

\section{Ensaios de Resistência a Compressão Simples}

Os resultados obtidos nos ensaios de compressão simples realizados por Silva (2003) e Barbosa (2017), para o material presente na base, meio e topo da falésia, estão apresentados nas tabelas 1 e 2 . Os dados mostram que, apesar de parecer homogêneo visivelmente, o material do topo apresenta uma variabilidade considerável com relação a resistência a compressão simples, com mínimo de 294,1 kPa, máximo de $808 \mathrm{kPa}$ e valor médio de $479,1 \mathrm{kPa}$. Essa característica pode ser atribuída, sobretudo aos diferentes graus de cimentação entre as partículas. O material da base apresenta valores mais altos de resistência variando de $484,2 \mathrm{kPa}$ a $936 \mathrm{kPa}$ (valor médio de $628,9 \mathrm{kPa})$.

$\mathrm{O}$ índice de vazios apresenta variação de cerca de $57 \%$, para as amostras retiradas da base da falésia $(0,35$ a 0,55$)$.

Além disso, verifica-se que não existe uma relação direta entre o índice de vazios e a resistência em alguns exemplos. Comparando as amostras 6 e 7, nota-se que o índice de vazios apresenta o mesmo valor $(0,68)$, enquanto que o 
valor de resistência a compressão varia de 808 $\mathrm{kPa}$ para $336 \mathrm{kPa}$.

Nas amostras 8 e 17, observa-se o comportamento inverso, onde existe grande variação no índice de vazios e pequena variação no valor da resistência.

Entretanto, o material da base evidencia os menores valores de índice de vazios relacionados com maiores valores de resistência a compressão simples (amostra 16).

Tabela 1 - Características iniciais dos corpos de prova e resistência a resistência à compressão simples (RCS) do material do topo e base da falésia do município de Tibau do Sul/RN. (Silva, 2003).

\begin{tabular}{c|c|c|c|c|c}
\hline Amostra & Localização & $\boldsymbol{\gamma}\left(\mathbf{k N} / \mathbf{m}^{\mathbf{3}}\right)$ & $\mathbf{e}$ & $\mathbf{S}(\boldsymbol{\%})$ & $\mathbf{R C S}(\mathbf{k P a})$ \\
\hline $\mathbf{1}$ & Topo & 15,62 & 0,72 & 4,72 & 393 \\
\hline $\mathbf{2}$ & Topo & 16,03 & 0,67 & 5,02 & 314 \\
\hline $\mathbf{3}$ & Topo & 15,97 & 0,68 & 4,97 & 380 \\
\hline $\mathbf{4}$ & Topo & 15,94 & 0,68 & 4,95 & 393 \\
\hline $\mathbf{5}$ & Topo & 16,23 & 0,65 & 5,18 & 550 \\
\hline $\mathbf{6}$ & Topo & 16,01 & 0,68 & 5,01 & 336 \\
\hline $\mathbf{7}$ & Topo & 15,98 & 0,68 & 4,98 & 808 \\
\hline $\mathbf{8}$ & Topo & 16,16 & 0,66 & 5,13 & 619 \\
\hline $\mathbf{9}$ & Topo & 16,22 & 0,65 & 5,17 & 610 \\
\hline $\mathbf{1 0}$ & Topo & 15,80 & 0,70 & 4,85 & 494 \\
\hline $\mathbf{1 1}$ & Topo & 15,57 & 0,72 & 4,48 & 380 \\
\hline $\mathbf{1 2}$ & Topo & 15,81 & 0,70 & 5,09 & 520 \\
\hline $\mathbf{1 3}$ & Topo & 16,92 & 0,59 & 5,85 & 617 \\
\hline $\mathbf{1 4}$ & Base & 19,40 & 0,38 & 5,47 & 605 \\
\hline $\mathbf{1 5}$ & Base & 19,00 & 0,40 & 4,54 & 610 \\
\hline $\mathbf{1 6}$ & Base & 19,78 & 0,35 & 6,55 & 936 \\
\hline $\mathbf{1 7}$ & Base & 19,20 & 0,39 & 5,38 & 611 \\
\hline
\end{tabular}

Tabela 2 - Características iniciais dos corpos de prova e resistência a resistência à compressão simples (RCS) do material do topo, meio e base da falésia Barreira do Inferno. (Barbosa, 2017).

\begin{tabular}{c|c|c|c|c|c}
\hline Amostra & Localização & $\boldsymbol{\gamma}\left(\mathbf{k N} / \mathbf{m}^{\mathbf{3}}\right)$ & $\mathbf{e}$ & $\mathbf{w}(\boldsymbol{\%})$ & $\mathbf{R C S}(\mathbf{k P a})$ \\
\hline $\mathbf{1}$ & Topo & 17,20 & 0,54 & 1,97 & 294,1 \\
\hline $\mathbf{2}$ & Meio & 17,30 & 0,53 & 1,41 & 440,7 \\
\hline $\mathbf{3}$ & Meio & 17,70 & 0,49 & 1,41 & 496,7 \\
\hline $\mathbf{4}$ & Base & 17,70 & 0,55 & 3,84 & 484,2 \\
\hline $\mathbf{5}$ & Base & 18,10 & 0,51 & 3,84 & 527,4 \\
\hline
\end{tabular}

De acordo com a classificação proposta por Collins e Sitar (2009), constata-se que o material do topo das falésias de Tibau do Sul e Barreira do Inferno apresentam-se divididos entre moderadamente cimentado $(100 \mathrm{kPa}<\mathrm{RCS}<$ $400 \mathrm{kPa}$ ) e fortemente cimentada (RCS > 400 $\mathrm{kPa}$ ). O material da base e do meio das falésias analisadas podem ser classificados como fortemente cimentados.

De forma geral, os corpos de prova retirados em Tibau do Sul apresentaram planos de ruptura bem definidos, os quais se iniciam nas extremidades e percorrem os corpos de prova longitudinalmente.

Porém, nos casos em que a tensão de ruptura aplicada foi acima da média (amostras 5, 7, 8, 9, $10,12,13$ e 16), ocorreu ruptura do tipo frágil da amostra, dividindo-se em vários fragmentos.

\section{Ensaios Resistência ao Cisalhamento}

A tabela 3 mostra os valores dos parâmetros de resistência de pico (coesão e ângulo de atrito), obtidos em ensaios triaxiais e cisalhamento direto realizados em diferentes amostras de solo provenientes da Formação Barreiras.

Através dos dados, é possível perceber que existe uma variabilidade muito grande no que diz respeito à coesão do material $(0 \mathrm{kPa}$ a $396,6 \mathrm{kPa})$. Os valores de coesão podem ser atribuídos a sucção e a cimentação entre as partículas.

Os valores máximos e mínimos do parâmetro coesão, obtidos em ensaios na condição inundada e natural em amostras de sedimentos provenientes da Formação Barreiras, são evidenciados na figura 6 . 
Constata-se a perda de cerca de $80 \%$ no valor do intercepto de coesão quando ocorre a saturação do material. Esse fato ocorre, pois a maior parte do valor de coesão é derivada da sucção do material nas amostras na condição natural (valores em preto e cinza no gráfico). Observa-se que a sucção exerce forte influência no comportamento resistente do material.

Tabela 3 - Parâmetros de resistência dos solos provenientes da Formação Barreiras.

\begin{tabular}{|c|c|c|c|c|c|}
\hline Localização & $\begin{array}{l}\text { Tipo de } \\
\text { ensaio }\end{array}$ & Amostra & c (kPa) & $\phi\left(^{\circ}\right)$ & Referência \\
\hline \multirow{3}{*}{ Tibau do Sul/RN } & \multirow{3}{*}{$\begin{array}{l}\text { Cisalhamento } \\
\text { Direto }\end{array}$} & Natural & $193,0-318,0$ & $43,0-52,0$ & \multirow{2}{*}{ Silva (2003) } \\
\hline & & Inundada & $45,0-53,0$ & $27,0-29,0$ & \\
\hline & & Natural & $233-396,6$ & & \\
\hline Tibau do Sul - RN & $\begin{array}{c}\text { Cisalhamento } \\
\text { Direto } \\
\end{array}$ & Inundada & $45,4-109,7$ & $27,7-48,3$ & Severo (2005) \\
\hline \multirow{2}{*}{ Tibau do Sul/RN } & \multirow{2}{*}{$\begin{array}{l}\text { Cisalhamento } \\
\text { Direto }\end{array}$} & Natural & $116,0-192,0$ & $27,0-32,0$ & \multirow{2}{*}{ Severo et al. (2006) } \\
\hline & & Inundada & $23,0-54,0$ & $26,0-30,0$ & \\
\hline $\begin{array}{c}\text { Ponta do } \\
\text { Pirambu/RN }\end{array}$ & Triaxial (CD) & $\begin{array}{c}\text { Compactada } \\
\text { Natural }\end{array}$ & $8,36,5-110,5$ & $28,429,4-33,0$ & Severo (2011) \\
\hline \multirow{2}{*}{ Baía Formosa /RN } & \multirow{2}{*}{$\begin{array}{l}\text { Cisalhamento } \\
\text { Direto }\end{array}$} & Natural & - & - & \multirow{2}{*}{ Souza Jr. (2013) } \\
\hline & & Inundada & $16,9-59,9$ & $29,5-33,6$ & \\
\hline $\begin{array}{l}\text { Barreira do } \\
\text { Inferno/RN }\end{array}$ & Triaxial (CW) & Natural & $97,6-192,1$ & $30,8-36,4$ & $\begin{array}{c}\text { Barbosa (2017); } \\
\text { Taquez (2017) }\end{array}$ \\
\hline $\begin{array}{l}\text { Barreira do } \\
\text { Inferno/RN }\end{array}$ & Triaxial (CU) & Saturada & $16,7-60,6$ & $12,1-28,9$ & $\begin{array}{c}\text { Barbosa (2017); } \\
\text { Taquez (2017) }\end{array}$ \\
\hline \multirow{2}{*}{$\begin{array}{l}\text { Zona oeste de } \\
\text { Natal/RN }\end{array}$} & \multirow{2}{*}{$\begin{array}{c}\text { Cisalhamento } \\
\text { Direto }\end{array}$} & Natural & $0,5-206,2$ & $19,5-43$ & \multirow{2}{*}{ Sousa (2018) } \\
\hline & & Inundada & $0-0$ & $32,9-36,9$ & \\
\hline \multirow{2}{*}{$\begin{array}{l}\text { Zona oeste de } \\
\text { Natal/RN }\end{array}$} & \multirow{2}{*}{$\begin{array}{c}\text { Cisalhamento } \\
\text { Direto }\end{array}$} & Natural & $148,6-306,8$ & $37,6-58,1$ & \multirow{2}{*}{ Sousa (2018) } \\
\hline & & Inundada & $17,5-106,7$ & $27,2-33,6$ & \\
\hline
\end{tabular}

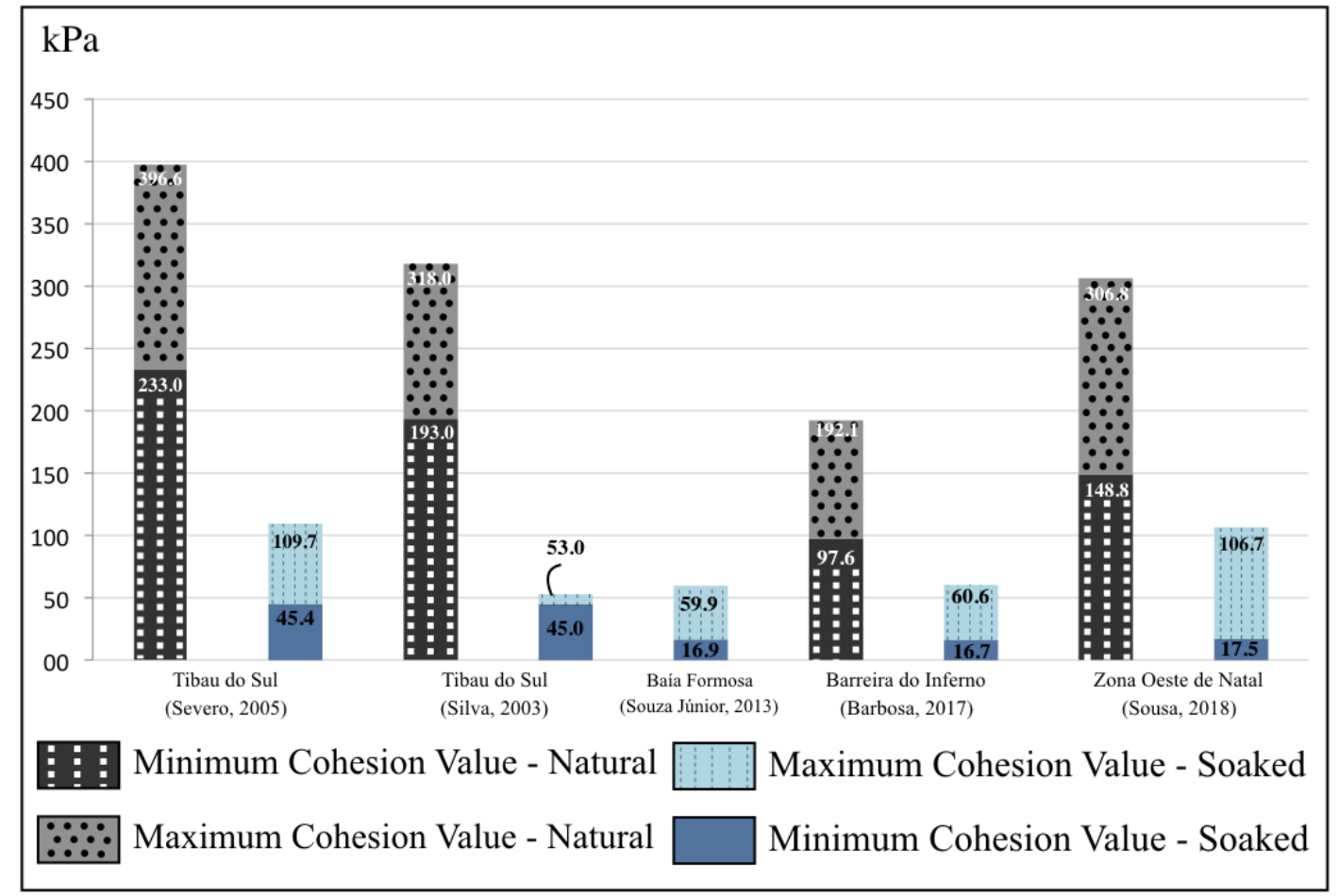

Figura 6 - Valores máximos e mínimos do parâmetro coesão, em ensaios na condição natural e na condição inundada.

A parcela restante do intercepto de coesão (valores em tons de azul no gráfico) é a coesão verdadeira, a qual é independente da condição de saturação do solo.

Assim, quando ocorre a saturação do material, essa parcela de coesão advinda da 
sucção é eliminada e diminui a capacidade resistente do maciço.

O ângulo de atrito também apresenta variação quando comparado os valores obtidos em ensaios na condição natural e inundada, porém não é representativa.

A figura 7 mostra dois histogramas (a) e (b),

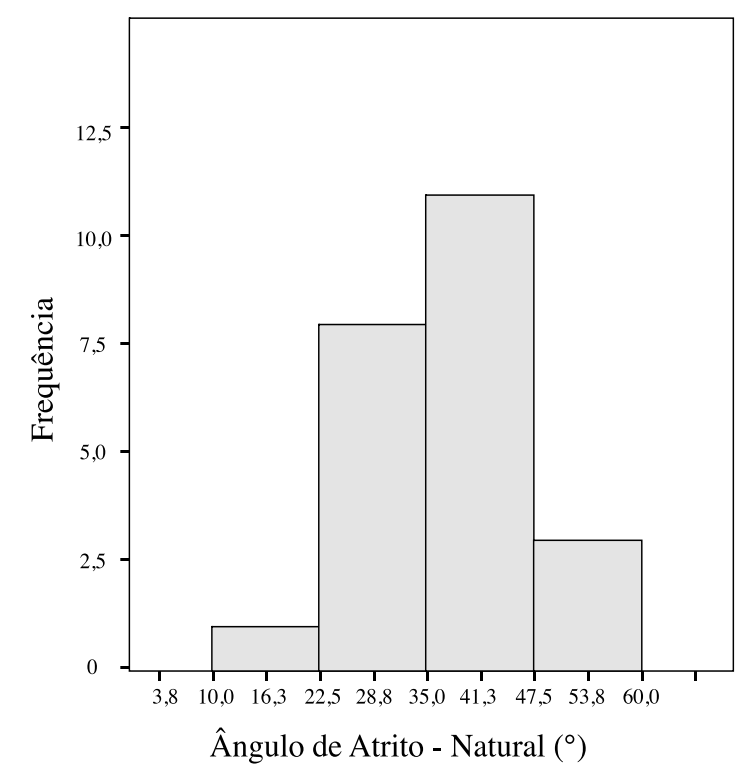

os quais apresentam os dados obtidos para o ângulo de atrito no estado natural e inundado, respectivamente. Os resultados dos ensaios na condição natural apontam uma variação de $19.5^{\circ}$ a $58.1^{\circ}$ (figura 7.a). Os ângulos de atrito obtidos nos ensaios inundados apresentam valores entre $12.1^{\circ}$ e $36.9^{\circ}$ (figura 7.b).

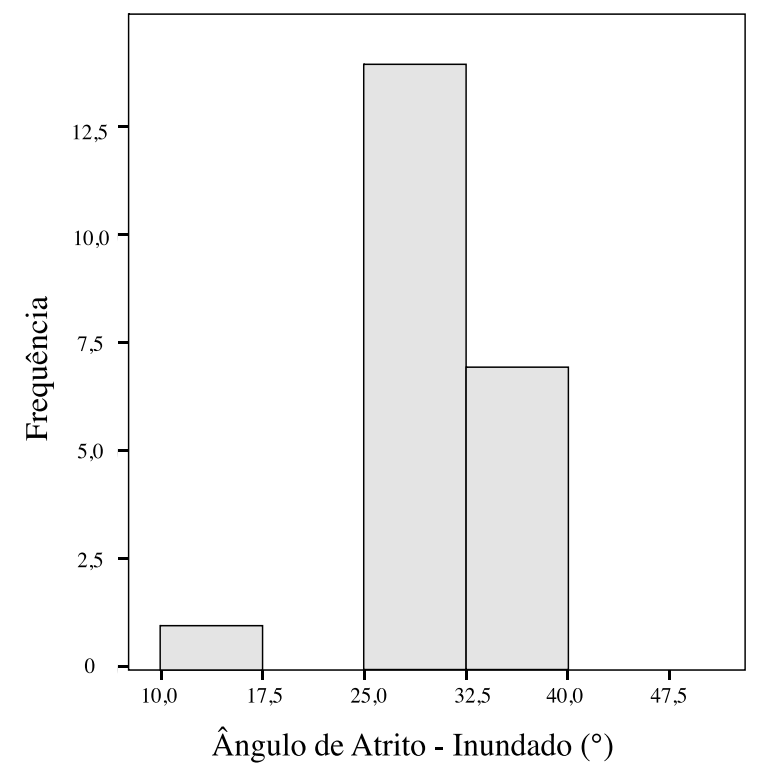

Figura 7 - Histogramas do parâmetro ângulo de atrito em amostras provenientes da Formação Barreiras. a) Valores obtidos através de 23 dados em amostras no estado natural.; b) Valores obtidos através de 22 dados em amostras no estado inundado (Silva, 2003; Severo, 2005; Severo, 2011; Souza Júnior, 2013; Barbosa, 2017; Taquez, 2017; Sousa, 2018).

O material no estado natural apresenta ângulo de atrito com maior número de ocorrências entre $35^{\circ}$ e $47.5^{\circ}$, mais próximo do comportamento de rochas. A forma do histograma de frequência para o ângulo de atrito na condição saturada, se aproxima do mesmo na condição natural, entretanto existe uma maior concentração de valores próximo da média. Nota-se de forma geral que, apesar de existir um valor bem distinto $\left(12,1^{\circ}\right)$ do comumente observado para esse parâmetro no estado inundado, o ângulo de atrito tende a se manter dentro da faixa de variação de valores listada por Severo (2011) para a Formação Barreiras, ou seja, valores de ângulos de atrito correspondente à materiais arenosos (entre $29^{\circ}$ e $32^{\circ}$ ). As maiores variações nos valores de ângulo de atrito ocorrem nas amostras de maior heterogeneidade (Sousa, 2018).

\section{PROCESSOS EROSIVOS E MOVIMENTOS DE MASSA}

Os dados disponíveis de trabalhos anteriores, tanto relacionados à caracterização geotécnica dos materiais como às análises de estabilidade, representam uma importante base para determinar os principais mecanismos, modos de ruptura e também condições limites para a ocorrência de movimentos de massa. Segundo Collins \& Sitar, 2008, os mecanismos de ruptura podem ser descritos como as causas diretas do movimento de massa, enquanto que o modo de ruptura é a definição do tipo de movimento que ocorre na ruptura das falésias.

De forma geral, as falésias de toda a área estudada possuem características típicas, bem como processos erosivos similares, dependendo principalmente das condições ambientais e antrópicas.

Nos setores em que o mar alcança as falésias e o pé da encosta não é protegido por blocos de arenitos, o impacto das ondas incide diretamente na base das falésias, formando incisões basais e pontos de instabilidade (Figura 8). Essas incisões, normalmente causam a queda de blocos e tombamentos, tanto na parte do topo das falésias, como na zona diretamente acima da incisão. Esse processo dinâmico e contínuo resulta no recuo costeiro.

Os blocos que caem na praia se desintegram e podem ser incorporados à dinâmica costeira e serem transportados pelas correntes da deriva 
litorânea. Eventualmente, quando os blocos são mais resistentes, não são se desintegram e a água não tem energia suficiente para transportá-los. Assim, permanecem do local da queda e passam a proteger a base da falésia contra a ação das ondas (Figura 9).

De acordo com as análises de tensão $\mathrm{x}$ deformação realizadas em Silva et al. (2016), à medida que a incisão basal progride percebe-se um aumento da inclinação da falésia e uma mudança nas tensões na região adjacente à incisão. Nessas condições, surgem esforços de tração na parte imediatamente acima da incisão e na face da falésia.

Quando os esforços de tração impostos à falésia pela formação da incisão na sua base se igualam aos valores de resistência à tração do material ocorre a ruptura na forma de destacamento de blocos e lascas do material das falésias. Esse quadro se agrava no período de chuvas, uma vez que o umedecimento do material provoca o aumento das tensões atuantes e a diminuição da resistência.

Os resultados obtidos em Taquez (2017) ratificam essas observações. As encostas se tornam mais instáveis com o aumento da extensão da incisão basal.

Além disso, à medida que a frente de umedecimento do maciço avança, a extensão máxima estável do entalhe formado pelo corte das ondas na base das falésias diminui.

Esse comportamento é evidenciado por quedas de blocos, tombamentos e deslizamentos em áreas próximas às incisões basais, bem como pela maior ocorrência registrada nos períodos de chuvas (Figura 8)..
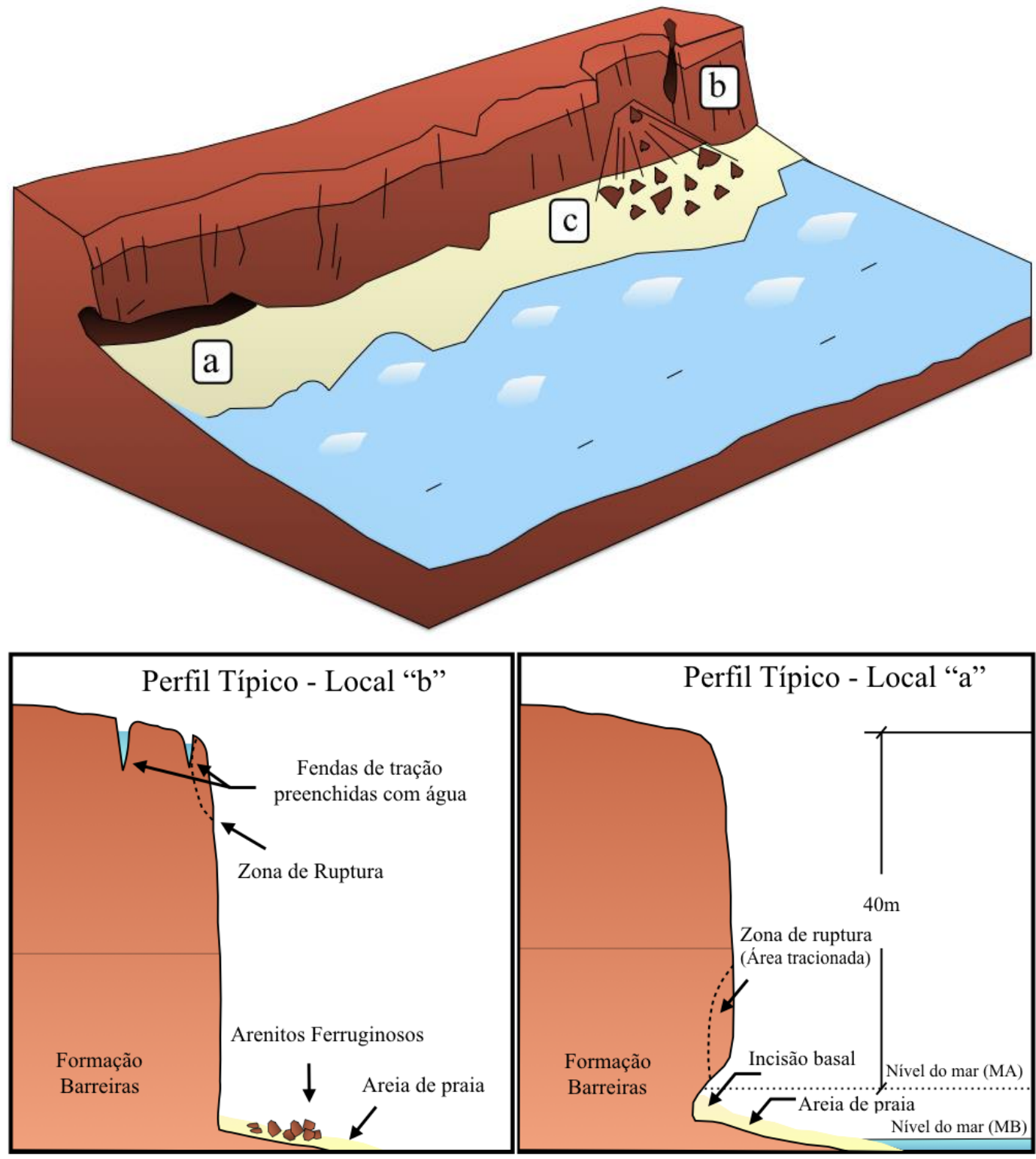

Figura 8 - Perfis Típicos - a) Esquema geral do processo de erosão basal na falésia e movimentos de massa. Destaca-se a formação de um entalhe na base da falésia; b) Formação de fendas de tração sub-verticais, mediante a ação das chuvas. No esquema geral, ponto "c" mostra a ocorrência de movimentos de massa e acúmulo de talus na base. 
Nas áreas com maiores faixas de praia o mar não atinge a base das falésias. Assim, os sedimentos praiais atuam como proteção contra a ação das ondas.

Outro fator de controle e proteção (retardador) contra ação direta das ondas é a ocorrência dos blocos de arenitos com cimentação ferruginosa (sedimentos) ao longo da base das falésias, provenientes da Formação Barreiras.

Os taludes presentes nas áreas onde o mar não atinge as falésias apresentam menores inclinações que àqueles onde há a ação do mar na sua base.

Em geral ocorrem ângulos de $40^{\circ}$ a $60^{\circ}$ e resultam do equilíbrio do talude frente aos processos continentais a que estão submetidos. Nesse sentido, destaca-se a ação da água de chuva que pode provocar erosão na face do talude ou deslizamentos devido a infiltração. Em alguns casos observa-se a presença de vegetação revestindo a falésia (Figura 10).

Outra característica importante observada nas investigações de campo é a formação de sulcos, ravinas e voçorocas, no topo das falésias, por meio da erosão pluvial, sobretudo nas regiões desprovidas de cobertura vegetal.

A formação dessas feições erosivas pode ser facilmente identificada próxima de dispositivos de drenagem de estradas localizadas ao lado das falésias (Santos Jr. et al., 2011).

Além dessa particularidade, as falésias apresentam fendas de tração, as quais potencializam a ocorrência de movimentos de massa e quedas de blocos.

Em episódios de chuvas intensas, essas fendas podem provocar quedas de blocos e tombamentos, principalmente se estiverem preenchidas com água (Figura 8). Essas observações são confirmadas segundo as análises realizadas em Taquez et al. (2016) e Taquez (2017).

As chuvas também exercem influência induzindo o aumento do grau de saturação do maciço e consequentemente a redução da resistência ao cisalhamento.

O aumento do grau de saturação do material causa a diminuição do intercepto de coesão do solo (parcela referente a sucção matricial), e, portanto, a resistência ao cisalhamento diminui bruscamente (Santos Jr. et al., 2011).

Segundo os resultados obtidos em Taquez (2017), nessas condições as falésias apresentamse instáveis, ocasionando movimentos de massas.

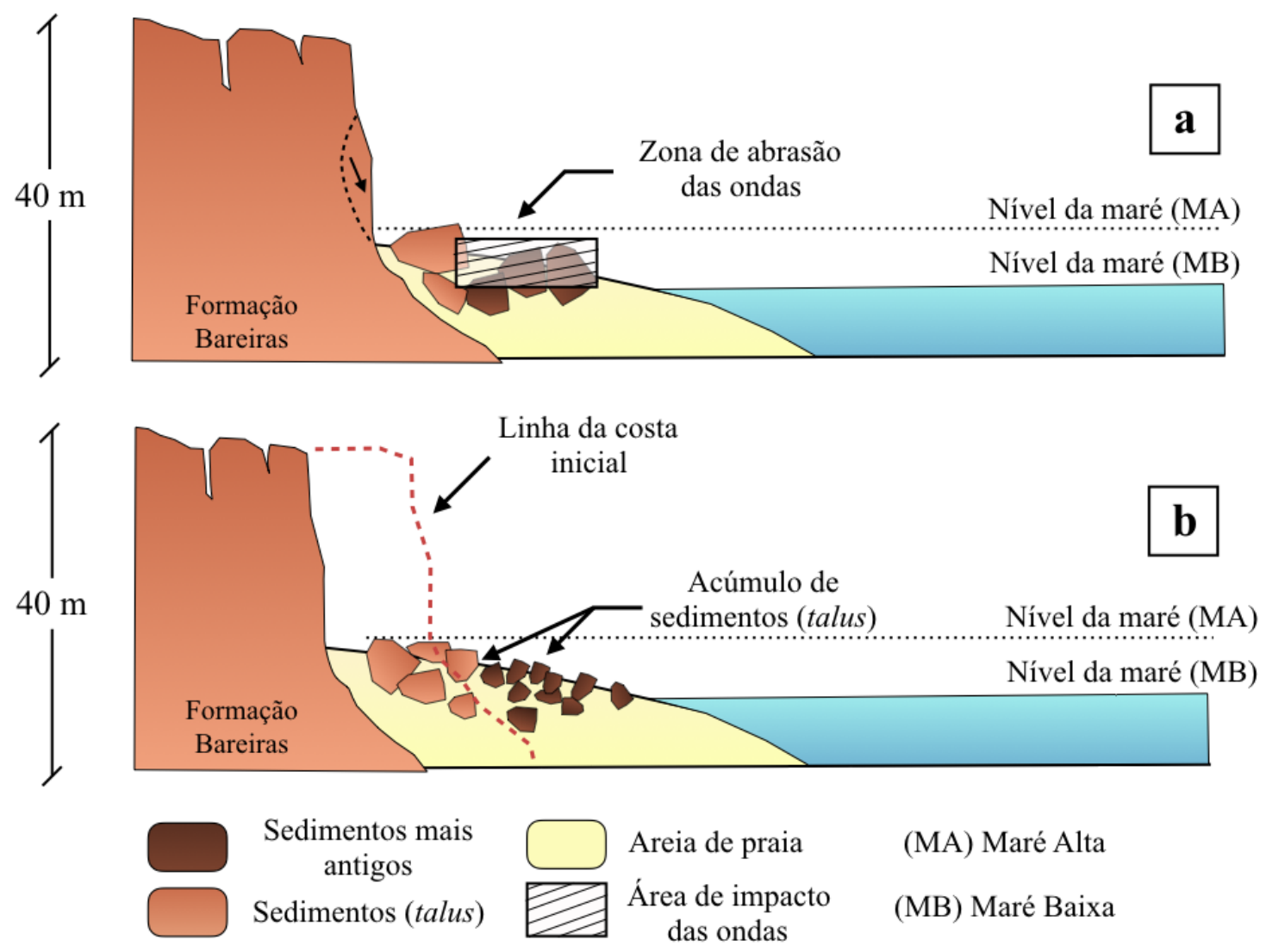

Figura 9 - Modelo de evolução dos blocos de sedimentos ferruginosos. a) Falésias sofrendo impacto direto da ação das ondas, proporcionando movimentos de massa e acúmulo de talus na base das falésias; b) Recuo costeiro e nova posição dos blocos (sedimentos), protegendo cada vez mais a base das falésias. 


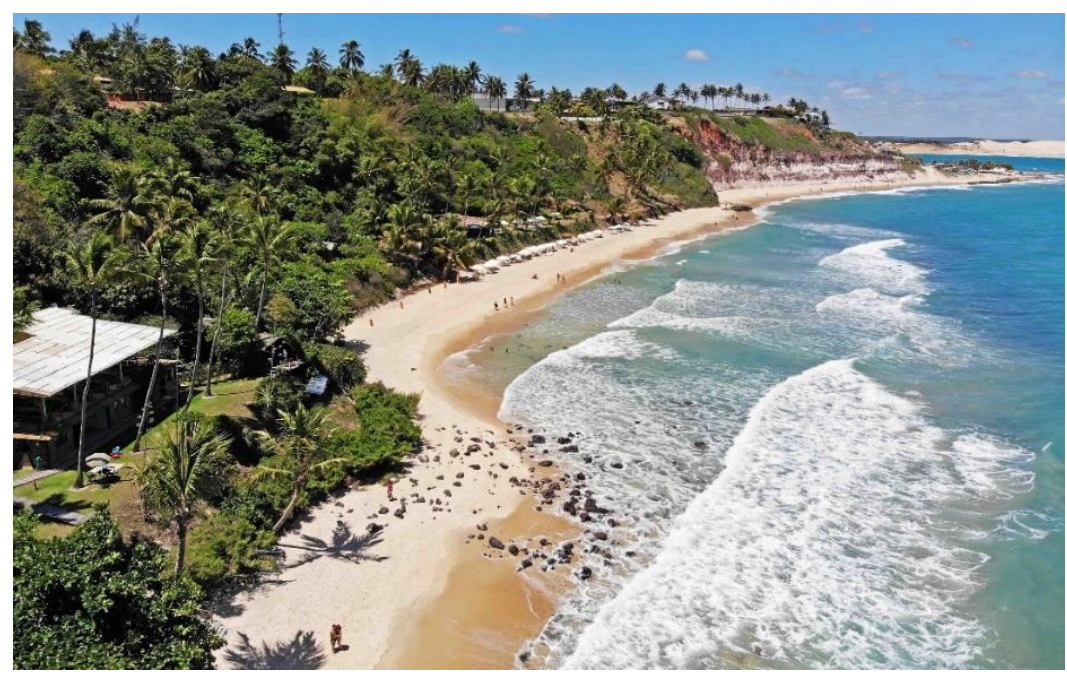

Figura 10 - Área onde o mar não atinge a base da falésia: taludes mais suaves que permitem o surgimento de vegetação. Ponta do Pirambu em Tibau do Sul.

\section{PROPOSTA DE UM MODELO PARA O RECUO DAS FALÉSIAS}

Apresenta-se a seguir um modelo conceitual para a explicar os processos erosivos costeiros no litoral sul do RN. Considera-se que as falésias estão submetidas a processos marinhos e continentais.

Em termos de processo marinho destaca-se a ação das águas na base das falésias. Os processos continentais estão relacionados a ação do escoamento superficial e da infiltração de águas de chuva no talude. Esses processos induzem movimentos de massas que resultam no recuo costeiro. Alguns outros componentes atuam no sentido de acelerar ou de retardar os processos. No sentido de acelerar o recuo destacam-se a abertura de fendas de tração na parte superior das
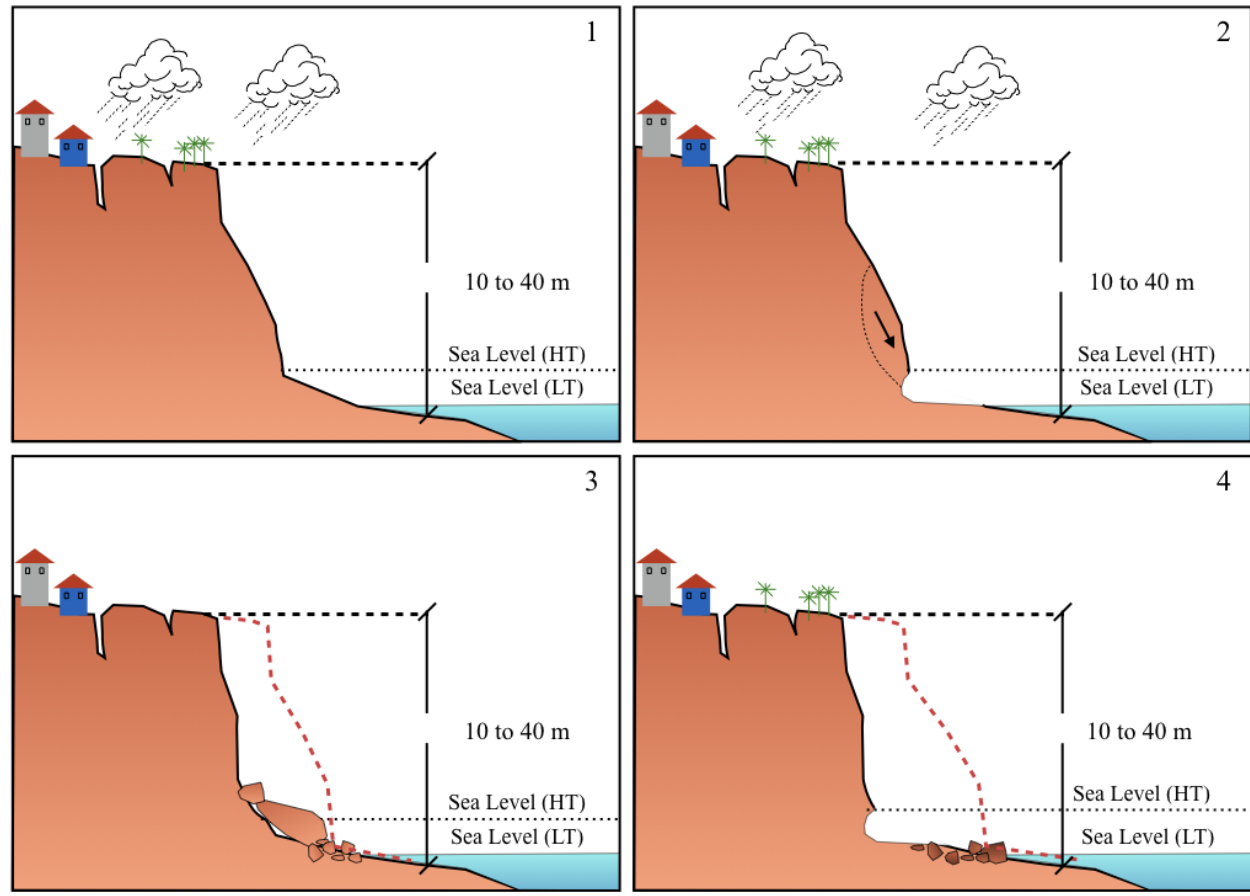

Figura 11 - Resumo do processo de erosão costeira proporcionando movimentos de massa como quedas e tombamentos e consequentemente o recuo da linha de costa.

São Paulo, UNESP, Geociências, v. 39, n. 2, p. 447 - 461, 2020 
A ação antrópica também pode alterar essa dinâmica natural. As alterações decorrem principalmente das intervenções que modificam a drenagem natural das águas de chuva e concentram o fluxo em determinados pontos. Esses aspectos promovem a concentração de energia das águas que facilitam a ocorrência de processos erosivos.

Construções próximas a crista das falésias também induzem aumento das tensões cisalhantes no maciço e podem provocar a ruptura dos taludes

\section{CONCLUSÕES}

Este artigo sistematiza o estado da arte sobre os principais mecanismos de ruptura e processos erosivos localizados na porção sul do litoral Oriental do Estado do RN. Identificar condições limites de estabilidade para as falésias da Formação Barreiras, baseadas nas mudanças do ambiente e dos principais parâmetros que controlam o processo, representa um importante passo para auxiliar no controle de riscos costeiros e políticas de uso e ocupação do solo. Além disso, estudos dessa natureza colaboram para a avaliação das implicações práticas do crescimento desordenado de áreas costeiras.

O processo de recuo costeiro observado na área de estudo é cíclico e dinâmico. Através dos processos erosivos devidos tanto às chuvas quanto ao impacto das ondas na base das falésias.

A taxa de ocorrência desse processo dependerá de diversos fatores correlacionados, que contribuem para a ocorrência dos movimentos de massa, tais como: resistência dos materiais, morfologia das falésias, ação das águas das chuvas e marés, ocorrência da vegetação e ação antrópica. À medida que os processos erosivos e movimentos de massa ocorrem, a influência dos parâmetros de controle muda.

A coesão resultante da cimentação entre as partículas corresponde à maior parcela da resistência do material da Formação Barreiras. Os valores de resistência à compressão simples do material apresentam-se divididos entre moderadamente cimentado $(100 \mathrm{kPa}<\mathrm{RCS}<$ $400 \mathrm{kPa}$ ), nas camadas do topo e fortemente cimentada $(\mathrm{RCS}>400 \mathrm{kPa})$, nas camadas mais próximas à base.

A ação das ondas e das chuvas podem ser considerados os principais mecanismos identificados no litoral Oriental do Estado do RN. Observa-se que os movimentos de massa ocorrem principalmente pelo aumento da inclinação das falésias e surgimento de esforços de tração na borda da falésia, devido a ação direta das ondas. Esse fato é somado com a frente de umedecimento do material através das chuvas, onde a parcela de coesão do material, derivada da sucção é eliminada e diminui a capacidade resistente das falésias. Ainda existe a influência das fendas de tração observadas nas bordas das falésias. Essas fendas quando preenchidas com água resulta em cargas de tração no interior do maciço de solo. Por isso, a maioria dos movimentos de massa ocorre nos períodos chuvosos.

Os modos de ruptura identificados são principalmente quedas e tombamentos em falésias mais íngremes e deslizamentos em falésias de inclinação mais amena.

\section{AGRADECIMENTOS}

Os autores agradecem ao Conselho Nacional de Desenvolvimento Científico e Tecnológico CNPq, (Processo n. 432226/2016-8, Edital Universal 01/2016) pelo apoio financeiro para a realização desse trabalho.

\section{REFERENCIAS}

AMARO, V.E.; SANTOS, M.S.T.; SOUTO, M.V.S. Geotecnologias aplicadas ao monitoramento costeiro: Sensoriamento Remoto e Geodésia de Precisão. 120 p. (2012). ISBN 978-85-913746-0-1.

BARBOSA, N.M. Estabilidade das falésias da Barreira do Inferno-RN. Natal. 2017. Dissertação (Mestrado), Universidade Federal do Rio Grande do Norte.

BELOV, A.P., DAVIES, P.; WILLIAMS, T. Mathematical modeling of basal coastal cliff erosion in uniform strata: A theoretical approach. The journal of geology, v. 107, p. 99$109,1999$.

BLANCO-CHAO, R.; PEDOJA, K.; WITT, C.; MARTINOD, J.;
HUSSON, L.; REGARD, V.; AUDIN, L.; NEXER, M.; DELCAILLAU, B.; SAILLARD, M., MELNICK, D., DUMONT, J. F.; SANTANA, E.; NAVARRETE, E.; MARTILLO, C.; PAPPALARDO, M.; AYALA, L.; ARAYA, J. F.; FEAL-PÉRES, A.; CORREA, D.; AROZARENALLOPIS, I. The rock coast South and Central America. Geological Society, London, Memoirs, v.40, p. 155 - 191, 2014.

BROOKS, S.M.; SPENCER, T.; BOREHAM, S. Deriving mechanisms and thresholds for cliff retreat in soft-rock cliffs under changing climates: Rapidly retreating cliffs of the Suffolk coast, UK. Geomorphology, v. 153-154, p.48 - 60, 2012. 
COLLINS, B.D. \& SITAR, N. Processes of coastal bluff erosion in weakly lithified sands, Pacifica, California, USA. Geomorphology, v. 97, p. 483 - 501, 2008.

COLLINS, B.D. \& SITAR, N. Geotechnical properties of cemented sands in steep slopes. Journal of geotechnical and geoenvironmental engineering, v. 135, n. 10, p. $1359-1366$, 2009.

DINIZ, R.F. A Erosão Costeira ao Longo do Litoral Oriental do Rio Grande do Norte: Causas, Consequências e Influências nos Processos de Uso e Ocupação da Região Costeira. Salvador. 2002. Tese (Doutorado em Geociências) Instituto de Geociências.

MARTINO, S. \& MAZZANTI, P. Analysis of sea cliff slope stability integrating traditional geomechanical surveys and remote sensing. Natural Hazards and Earth System Sciences, v. 1, p. 3689 - 3734, 2013.

MOORE, R. \& DAVIS, G. Cliff instability and erosion management in England and Wales. Journal of Coastal Conservation, v. 19, p. 771-784, 2015

MUEHE, D. Erosão e progradação no litoral brasileiro, 2014, 476 p. ISBN 85-7738-028-9.

NASCIMENTO, K.C. Monitoramento por DGPS e análise dos processos erosivos da linha de costa na praia de Pirangi do Norte - Parnamirim/RN. Natal. 2009. Dissertação (Mestrado). Universidade Federal do Rio Grande do Norte.

PIÉRRI, G.C.S. Análise de Risco à Erosão Costeira na Região de Tibau do Sul/RN Através de Mapeamento Geoambiental e Análise Morfodinâmica. Natal, 2008. Tese (Mestrado), Universidade Federal do Rio Grande do Norte.

QUINN, J.D.; PHILIP, L.K.; MURPHY, W. Understanding the recession of the Holderness Coast, east Yorkshire, UK: a new presentation of temporal and spatial patterns. Quarterly journal of engineering geology and hydrogeology, v. 42, p. $165-178,2009$.

RIBEIRO, J.R.C. Análise paramétrica da estabilidade de falésias e estudo de caso da Ponta do Pirambu em Tibau do Sul/RN. Natal. 2015. Dissertação (Mestrado), Universidade Federal do Rio Grande do Norte.

SANTOS JR., O.F.; AMARAL, R.F.; SCUDELARI, A.C. Failure mechanismos of a coastal cliff in Rio Grande do Norte State, NE, Brazil. JOURNAL OF COASTAL RESEARCH, SI 39 PROCCENDINGS OF THE 8TH INTERNATIONAL COASTAL SYMPOSIUM, Itajaí, 2006. Anais...Itajaí, 2006, p. 629-632.

SANTOS JR., O.F.; SCUDELARI, A.C.; COSTA, A.C.; COSTA, C. M. Sea Cliff retreat mechanisms in northeastern Brazil. JOURNAL OF COASTAL RESEARCH, SI 64 PROCCENDINGS OF THE 11TH INTERNATIONAL COASTAL SYMPOSIUM, Szczecin, Poland, 2011. Actas... Szczecin. ISSN 0749-0208.

SCUDELARI, A.C.; BRAGA, K.G.; COSTA, F.A.A.; SANTOS JR., O.F. Erosive processes study that affecting Pipa beach RN. Braz. J. Aquat. Sci. Technol., v. 9, n. 1, p. 31-37, 2005. ISSN 1808-7035.

SEVERO, R.N. F. Análise da estabilidade das falésias entre Tibau do Sul e Pipa-RN. Natal. 2005. Dissertação (Mestrado), Universidade Federal do Rio Grande do Norte,

SEVERO, R.N.F. Caracterização geotécnica da falésia da Ponta do Pirambu em Tibau do Sul-RN considerando a influência do comportamento dos solos nos estados indeformado e cimentado artificialmente. Recife. 2011. Tese (Doutorado em Engenharia Civil), Universidade Federal de Pernambuco.
SEVERO, R.N.F.; SANTOS JR., O.F.; FREITAS NETO, O. Propriedades geotécnicas de sedimentos da formação barreiras no litoral do Rio Grande do Norte. In: CONGRESSO BRASILEIRO DE MECÂNICA DOS SOLOS E ENGENHARIA GEOTÉCNICA, 13, Curitiba. 2006. Anais... Curitiba: COBRAMSEG, 2006, v. 1.

SILVA, W.S. Estudo da Dinâmica Superficial e Geotécnico das Falésias do Município de Tibau do Sul - Litoral Oriental do RN. Natal. 2003. Dissertação (Mestrado), Universidade Federal do Rio Grande do Norte.

SILVA, B.M.F.; FREITAS NETO, O.; SANTOS JÚNIOR, O.F.; BARBOSA, N.M.; FRANÇA, F.A.N.; ARAÚJO, E.E.B. Stability Evolution with Basal Erosion Increase in Cliffs on the Coast of Rio Grande do Norte, Brazil. Applied Mechanics and Materials, v. 858, p. 342-347, 2016. ISSN: 1662-7482,

SOUSA, R.A. Resistência e Compressibilidade de Solos da Formação Barreiras da Região de Natal/RN. Natal. 2018. Dissertação (Mestrado). Universidade Federal do Rio Grande do Norte.

SOUZA JÚNIOR, C. Análise de estabilidade de falésias na zona costeira de Baía Formosa-RN. Natal. 2013. Dissertação (Mestrado). Universidade Federa do Rio Grande do Norte.

SUNAMURA, T. Rocky coast processes: with special reference to the recession of soft rock cliffs. Proceedings of the Japan academy ser B physical and biological sciences, v. 91, p. 481500, 2015.

TAQUEZ, D.E.D. Susceptibilidade à ocorrência de movimentos de massa e avaliação da estabilidade de falésias sob condição não saturada: Estudo de caso no Centro de Lançamentos da Barreira do Inferno - Brasil. Natal. 2017. Dissertação (Mestrado), Universidade Federal do Rio Grande do Norte,

TAQUEZ, D.E.D.; BARBOSA; S.B.M.F; FREITAS NETO, O.; SANTOS JÚNIOR, O.F. Estabilidade de Falésias no Litoral do RN Submetidas a Fendas de Tração e Incisão Basal. In: SIMPÓSIO DE RECURSOS HÍDRICOS DO NORDESTE, XIII, Aracaju, 2016. Anais...Aracaju: ABRH

VITAL, H.; SANTOS NETO, F.; PLÁCIDO JÚNIOR, J.S. Morfodinâmica de um canal de maré tropical: Estudo de caso na costa norte rio grandense, Nordeste do Brasil. Revista da Gestão Costeira, v. 8, n. 2, p. 113-126, 2008.

YOUNG, A.P. \& ASHFORD, S. Instability investigation of cantilevered sea cliffs. Earth surface processes and landforms, v. 33, p. $1661-1677,2008$.

YOUNG, A.P. Recent deep-seated coastal landsliding at San Onofre State Beach, California. Geomorphology, v. 228, p. $200-212,2015$. 